\title{
Research Article \\ Effect of Impeller Inlet Geometry on Cavitation Performance of Centrifugal Pumps Based on Radial Basis Function
}

\author{
Shuwei Zhang, Renhui Zhang, Sidai Zhang, and Junhu Yang \\ School of Energy and Power Engineering, Lanzhou University of Technology, Lanzhou 730050, China \\ Correspondence should be addressed to Renhui Zhang; zhangrhlut@163.com
}

Received 12 August 2016; Revised 19 October 2016; Accepted 3 November 2016

Academic Editor: Ryoichi Samuel Amano

Copyright ( 2016 Shuwei Zhang et al. This is an open access article distributed under the Creative Commons Attribution License, which permits unrestricted use, distribution, and reproduction in any medium, provided the original work is properly cited.

\begin{abstract}
Aiming at the cavitation problem, the blade leading edge shape has been changed to analyze its impact on the cavitation performance for centrifugal pumps. And the response model has been established based on the Radial Basis Function. The calculation case results show that the leading edge extending forward along the shroud can improve the inlet flow condition and cavitation performance. But the cavitation performance has been reduced immensely when the leading edge extends backward along the shroud. Along with the leading edge which extends forward along the hub, the cavitation performance increases at first and then decreases. A better cavitation performance for centrifugal pumps has lower load of blade inlet and higher pressure of blade suction side. The pressure pulsation is affected by the vortex out of the impeller and the falling-off and collapsing of the cavitation bubbles. The lower the pressure pulsation for blade passing frequency and the second harmonics of the samples is, the better the cavitation performance is. A relatively accurate response model based on the Radial Basis Function has been established to predict the effect of the shape of blade leading edge on the cavitation performance of centrifugal pumps.
\end{abstract}

\section{Introduction}

Cavitation is very complicated phenomenon that usually appears in the hydraulic machinery. It has serious impact on hydraulic performance and stability of pump. Cavitation will occur when the local pressure of liquid is lower than the vapor pressure. At that time, the vapor bubbles appear, develop, and collapse at high pressure area along with the motion of liquid [1]. In hydraulic machinery, the cavitation is very harmful. It will result in the vibration [2], noise [3,4], corrosion and damage [5] of flow passage components, performance decline [6] of hydraulic machinery, and so on.

In hydraulic machinery, there are many factors affecting the cavitation performance such as impeller inlet diameter, impeller hub diameter, blade inlet angles, shape of blade leading edge, blade passage throat area, blade thickness and number, blade surface roughness, suction chamber passage shape, and inducer shape. At present, aiming at these factors, many meaningful works have been done by researchers of this field. Schiavello and Visser [7] analyzed synthetically all these effect factors on the cavitation of pump and proposed a method to judge the standard of cavitation strength and control the development of bubbles. Wei et al. [8] considered the geometrical parameters of impeller and concluded a practical method to improve the cavitation performance of centrifugal pump. Acosta et al. [9] and Bakir et al. [10] contrasted different sweep angle of inducer blade leading edge and got the inducer blade leading edge with high cavitation performance, though analyzing the appearing and development of different type of cavitation. Balasubramanian et al. [11] contrasted different shape of blade leading edge and proposed that the parabolic blade leading edge will improve the cavitation performance and extend the life expectancy of impeller. Fan et al. [12] concluded that the bulge of blade leading edge towards the entrance direction of impeller is larger, and the cavitation performance of centrifugal pumps is worse. Yang et al. [13] proposed that appropriate extending of blade leading edge towards flow direction can improve the cavitation performance of double suction centrifugal pump effectively. Luo et al. [14] proposed that the flow uniformity of impeller inlet can effectively improve the cavitation performance of centrifugal pump through extending the blade leading edge and increasing the blade inlet angle. 
The shape of blade leading edge has great effect on the cavitation performance of centrifugal pump. In this research, the response model based on the Radial Basis Function (RBF) method has been proposed to predict the effect of shape of blade leading edge on the cavitation performance of centrifugal pump. The cavitation flow in the centrifugal pumps is simulated with steady and unsteady flow. The bubble distribution in the impeller, blade load, and the character of pressure fluctuation in different area of volute are analyzed for the design of experiments (DOE) samples. The approximate model between cavitation performance of centrifugal pumps and the shape of blade leading edge is established using the Radial Basis Function method.

\section{Radial Basis Function Technology}

2.1. Overview of the RBF. The Radial Basis Function is a kind of approximate interpolation method. In 1982, Franke [15] innovatively proposed to interpolate the random points on the dimensional surface by the RBF method and proved the reliability and accuracy of interpolation. Turk and O'brien [16] realized the reconstruction of complicated dimensional surface by interpolating the random points and selecting constraint points reasonably. Buhmann [17] proved the convergence of the approximate process of RBF method and the uniqueness of approximate solution existence and researched some new practical applications.

As a kind of interpolation method, the essence of RBF is to achieve the new datum fitting by learning from the existing datum. The stability and accuracy have been proved well. It has strong adaptation facing the complicated problems like high dimensions, multivariate, nonlinear, huge amount of datum, and so on. At present, the RBF method has been used in many fields such as surface reconstruction [18-21], mesh deformation [22-24], optimization method [25, 26], and fluid structure interaction [27].

2.2. Algorithm of the RBF. The formula of RBF is as follows:

$$
f(x)=\sum_{i=1}^{n} \lambda_{i} \phi\left(\left\|x-x_{i}\right\|\right),
$$

where $n$ is the amount of sample points, $x$ is the vector of design variable, $x_{i}$ is the vector of design variable at the $i$ th sample point, $\phi(r)$ is the Radial Basis Function, $\lambda_{i}$ is the coefficient at the $i$ th Radial Basis Function, and $\left\|x-x_{i}\right\|$ is the Euclidean norm, which is the Euclidean distance between the design variable and sample point. For the three-dimension space, it can be expressed as follows:

$$
r=\left\|x-x_{i}\right\|=\sqrt{\left(x-x_{i}\right)^{2}+\left(y-y_{i}\right)^{2}+\left(z-z_{i}\right)^{2}} .
$$

The common forms of Radial Basis Function are linear $(\phi(r)=r)$, cubic $\left(\phi(r)=r^{3}\right)$, thin-plate spline $(\phi(r)=$ $\left.r^{2} \ln (c r)\right)$, Gaussian $\left(\phi(r)=e^{-c r^{2}}\right)$, inverse multiquadric $\left(\phi(r)=1 / \sqrt{r^{2}+c^{2}}\right)$, and so on.

In general, the Radial Basis Function can be divided into three forms: global, local, and compact function [28]. The
TABLE 1: Hydraulic performance parameters.

\begin{tabular}{lcccc}
\hline $\begin{array}{l}\text { Flow } \\
\mathrm{m}^{3} / \mathrm{h}\end{array}$ & $\begin{array}{c}\text { Head } \\
\mathrm{m}\end{array}$ & $\begin{array}{c}\text { Rotate speed } \\
\mathrm{r} / \mathrm{min}\end{array}$ & $\begin{array}{c}\text { Efficiency } \\
\%\end{array}$ & $\begin{array}{c}\text { NPSHr } \\
\mathrm{m}\end{array}$ \\
\hline 120 & 61.09 & 2900 & 73 & 4.86 \\
200 & 52.35 & 2900 & 82.4 & 4.51 \\
240 & 45.34 & 2900 & 79.7 & 5.32 \\
\hline
\end{tabular}

Gaussian form belongs to the global function that the interpolation is dependent on all data points. And it is the strong nonlinear function which has a strong generalization ability and can adapt nonlinear problem perfectly. The advantage of the Gaussian has been proved in the interpolation of complex surface [29]. So the Gaussian has been used in this research, of which expression is

$$
\phi(r)=e^{-c r^{2}}
$$

where $c$ is a positive real number and $0 \leq c \leq 1$.

At first, a group of sample points $X=\left\{X_{1}, X_{2}, \ldots, X_{n}\right\}$ have been given in the Euclidean space. The corresponding function solutions are $f(x)=\left\{f_{1}, f_{2}, \ldots, f_{n}\right\}$. The corresponding RBF coefficients $\lambda_{i}=\left\{\lambda_{1}, \lambda_{2}, \ldots, \lambda_{n}\right\}$ at every sample points can be got by (1). Then the datum in the range of existing space can be predicted by interpolating the datum between every sample points according to (1).

The error must be considered in the response model, and the adjusted coefficient of multiple determinations $R_{\text {adj }}^{2}$ and the root mean square error RMSE are taken as the important reference, where the range of $R_{\text {adj }}^{2}$ is from 0 to 1 and the fitting accuracy is higher when $R_{\text {adj }}^{2}$ is close to 1 .

\section{Design of Experiments and the Numerical Simulation}

3.1. Design of Experiments. In this paper, the investigated prototype pump is M128-200 single-stage and single-suction centrifugal pump. The hydraulic performance parameters are given in Table 1.

In order to investigate the effect of the shape of blade leading edge on the cavitation performance, the blade leading edge is parameterized to get design of experiments samples, while the meridian shape of impeller remains unchanged.

In the meridian plane, the blade leading edge is extended along the shroud towards the direction of impeller entrance which is called the blade leading edge forward-sweep (FS) along the shroud. And the blade leading edge is extended along the shroud towards the direction of impeller exit which is called the blade leading edge back-sweep (BS) along the shroud. So the other two situations are, respectively, called the blade leading edge FS along the hub and the blade leading edge BS along the hub. The specific details are given in Figure 1.

In this research, the shape of the blade leading edge is parameterized by introducing the perturbation of the control variable FS and BS on shroud and hub. These perturbations are based on the prototype design. The parameter 


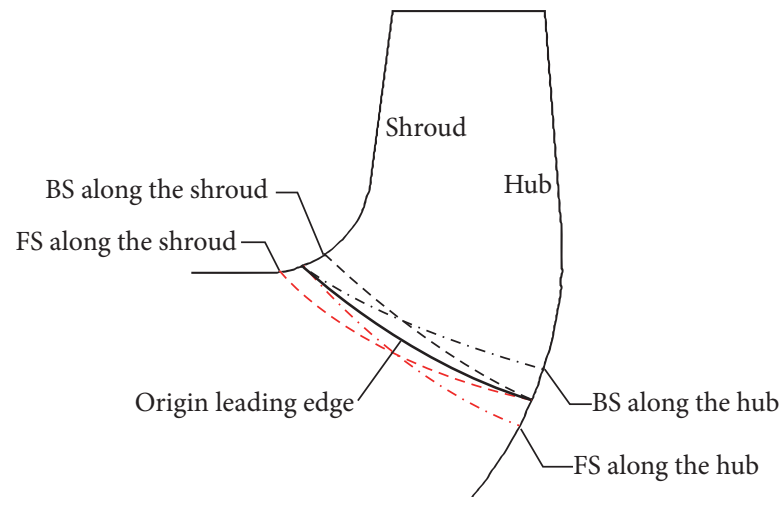

FIGURE 1: Sketch of blade leading edge position's change.

set ( \pm shroud, $\pm h u b$ ) is used to parameterize the centrifugal pump blade leading edge. In this set, shroud and hub represent, respectively, the angle of blade leading edge moving along the shroud and hub. The positive and negative represent, respectively, the FS and BS. The central composite design is implemented according to the parameter set. The design of experiments is as follows: $\left(0^{\circ}, 0^{\circ}\right),\left( \pm 10^{\circ}, 0^{\circ}\right),\left( \pm 20^{\circ}, 0^{\circ}\right)$, $\left(0^{\circ}, \pm 10^{\circ}\right)$, and $\left(0^{\circ}, \pm 20^{\circ}\right)$.

3.2. Numerical Simulation. The volumetric and disc friction losses are estimated using the experiential method. The computational domain includes section pipe, impeller, volute, and discharge pipe. Every computational domain is discretized, and the grids are closed at near wall area. The grid independency test which makes the change of hydraulic performance parameters within $0.5 \%$ is implemented and the grid number is 1.5 million.

The pump internal flow field is simulated using commercial software Fluent. The velocity and pressure are coupled by using SIMPLEC algorithm. The SST $\kappa-\omega$ turbulent model and the Zwart-Gerber-Belamri cavitation model are used. The average cavitation bubble diameter is $2 \times 10^{-6} \mathrm{~m}$, and the saturated vapor pressure is $3540 \mathrm{~Pa}$.

Firstly, the noncavitation flow in centrifugal pump is simulated, and then the steady cavitation simulation is on the basis of that result. The cavitation flow in centrifugal pump is simulated by reducing the pressure at pump inlet. Along with the decrease of inlet pressure, cavitation is aggravated in centrifugal pump and that leads to the decrease of every hydraulic performance parameter. The corresponding cavitation margin NPSHa is taken as the required cavitation margin NPSHr when the head declines about $3 \%$. The results of steady numerical simulation are taken as the initial value of unsteady numerical simulation. Time of centrifugal pump impeller rotating a circle is assumed as $T$. The time of impeller rotating $3^{\circ}$ is taken as a time step, so $\Delta T=T / 120=0.00017241 \mathrm{~s}$.

The hydraulic performance comparison between experiment and CFD result is presented in Figure 2. They match preferably.

\section{Results and Discussion}

4.1. Analysis of Impeller Internal Flow Field. Along with the decrease of pressure, cavitation appears and is aggravated

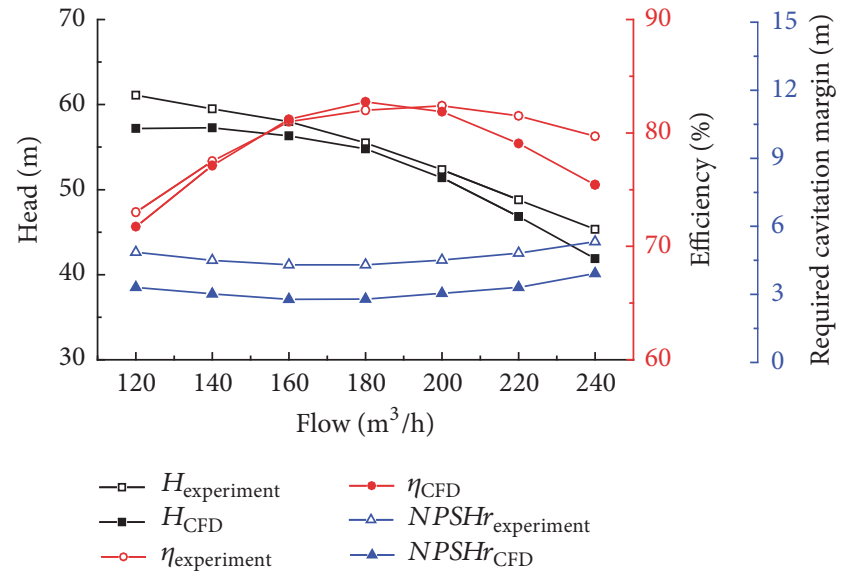

FIGURE 2: Hydraulic performance comparison between experiment and numerical simulation.

gradually in centrifugal pump. The cavitation bubbles initially appear at low pressure area of impeller which locates the blade suction side leading edge near shroud. When the cavitation is aggravated, bubbles extend gradually towards impeller outlet along the blade. The range of cavitation area becomes wider and extends towards blade pressure side. Therefore, the impeller passageway is blocked partly that makes the fluid get through the cavitation area quickly. Due to the enlarging of passageway behind the cavitation area, the velocity of fluid declines and results in that vortex forms at this area. In addition, the pressure difference between pressure side and suction side makes the vortex area stable. The cavitation performance curves of the blade samples are shown in Figure 3.

In Figure 3, when the inlet pressure is high, that is the noncavitation state and the head is unaffected. Along with the decrease of pressure, cavitation appears and is aggravated gradually in centrifugal pump, which leads to the decrease of the head. When the inlet pressure is lower enough, completely cavitation state is in the centrifugal pump, and the head drops steeply.

Blade FS along the shroud can promote the head and efficiency slightly and get better cavitation performance. Then blade BS along the shroud reduces the head, efficiency, and cavitation performance all. But the blades FS and BS along the hub can, respectively, promote and reduce the head and efficiency, and they all have slight effect on the cavitation performance.

When the angle of blades FS and BS along the shroud and hub is different, the corresponding cavitation performance is relatively different. The distribution of bubbles at the midspan is shown in Figure 4, when NPSHa is $3.31 \mathrm{~m}$.

As shown in Figure 4, the cavitation performance of centrifugal pump is greatly affected when the position of blade leading edge changes at the shroud. The blade FS along the shroud can observably reduce the range of cavitation area in impeller. Because pressure at blade suction side leading edge near the shroud is low relatively, the bubbles appear at that area. The fluid entering impeller gets the energy from blade, when the blade leading edge is FS along the 


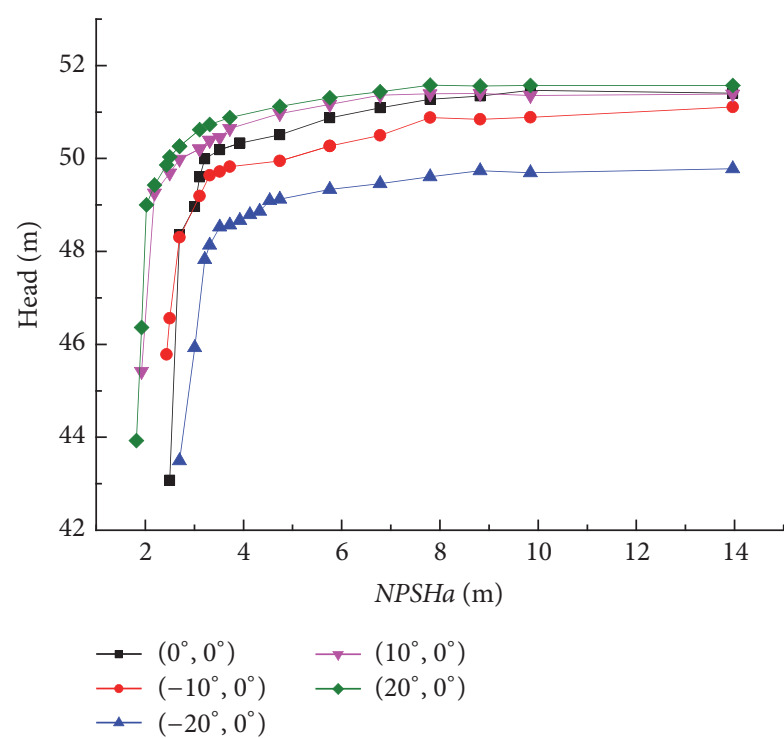

(a) Shroud

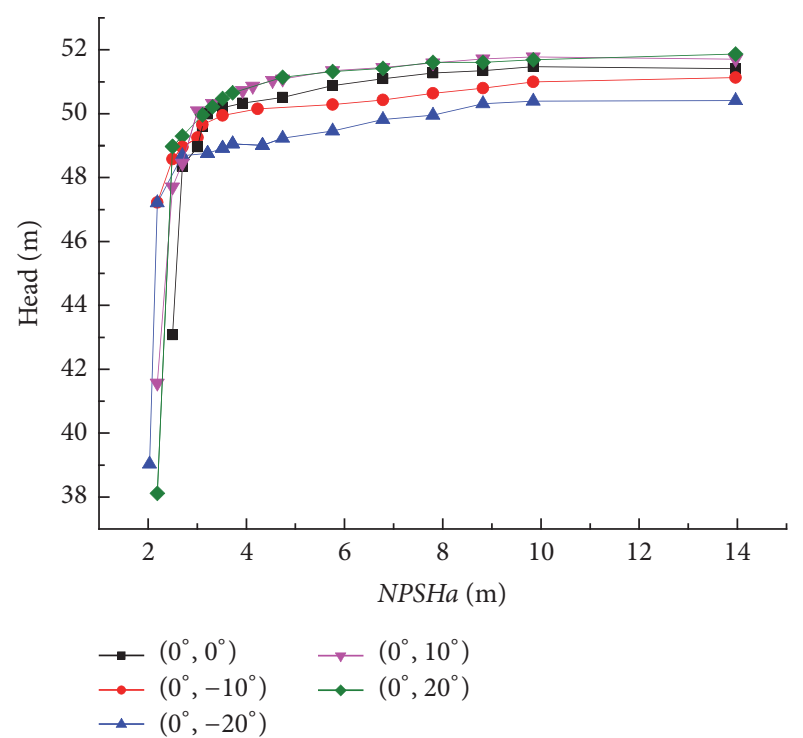

(b) Hub

FIGURE 3: Cavitation performance curves of blade samples.

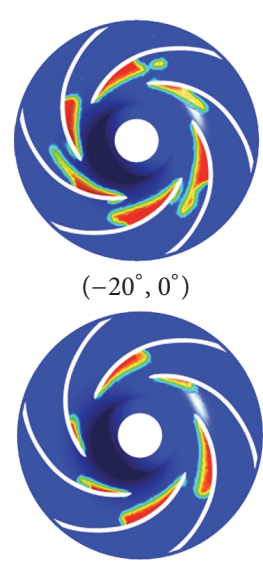

$\left(0^{\circ},-20^{\circ}\right)$

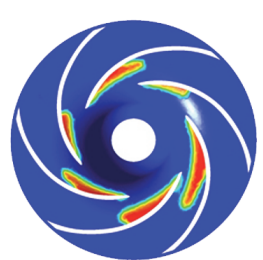

$\left(-10^{\circ}, 0^{\circ}\right)$

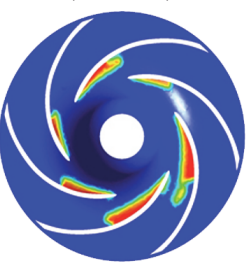

$\left(0^{\circ},-10^{\circ}\right)$

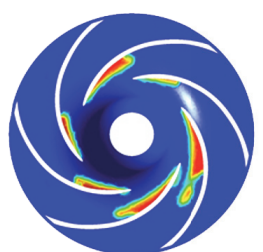

$\left(0^{\circ}, 0^{\circ}\right)$

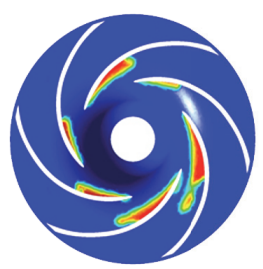

$\left(0^{\circ}, 0^{\circ}\right)$

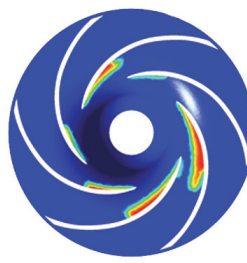

$\left(10^{\circ}, 0^{\circ}\right)$

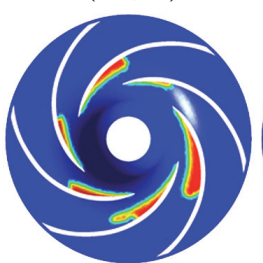

$\left(0^{\circ}, 10^{\circ}\right)$

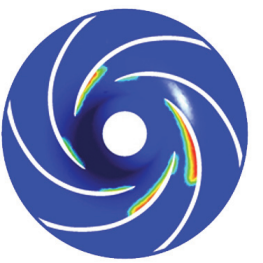

$\left(20^{\circ}, 0^{\circ}\right)$

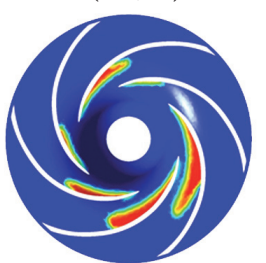

$\left(0^{\circ}, 20^{\circ}\right)$

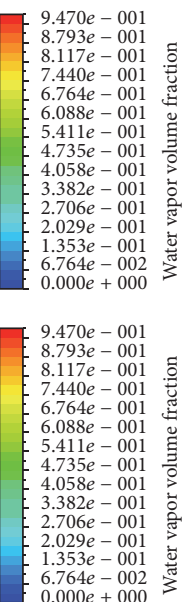

$6.764 e-002$
$0.000 e+000$

FIGURE 4: Distribution of bubbles at midspan when NPSHa is $3.31 \mathrm{~m}$.

shroud. The pressure at this area is promoted and the flow condition is improved at impeller entrance. So the cavitation performance is promoted. On the contrary, the blade BS along the shroud reduces cavitation performance greatly. However, the position of blade leading edge near the hub has slight effect on the cavitation performance of centrifugal pump. The distribution of bubbles at midspan changes little when the FS angle is small. But the bubbles area is enlarged apparently when the FS angle is large, as the impeller entrance passageway is blocked seriously by the oversize blade FS angle along the hub. The flow uniformity is destroyed that leads the decline of cavitation performance, while the blade BS along the hub has slight effect on the distribution of bubbles at midspan and the distribution area of bubbles is enlarged along with the increase of BS angle.

In addition, due to the asymmetry of volute passageway, the coupling between impeller and volute makes the asymmetry of blade surface pressure distribution. Consequently, the distribution of bubbles in each impeller passageway is asymmetric which is related to the relative position between blade and the tongue.

4.2. Analysis of Blade Load Distribution. The pressure between pressure side (PS) and suction side (SS) of same blade at same radius is taken as the blade load. The blade load distribution of different blade leading edge at midspan is shown in Figure 5.

The original blade load distribution is shown in Figure 5(a). The pressure change of pressure side is complicated. There is a pressure minimum at relative position 0.08 behind the blade entrance. It can be interpreted as that the boundary layer separation occurs around that place [30]. The pressure of suction side increases gradually. Along with the decline of inlet pressure, the pressure of pressure and suction side 


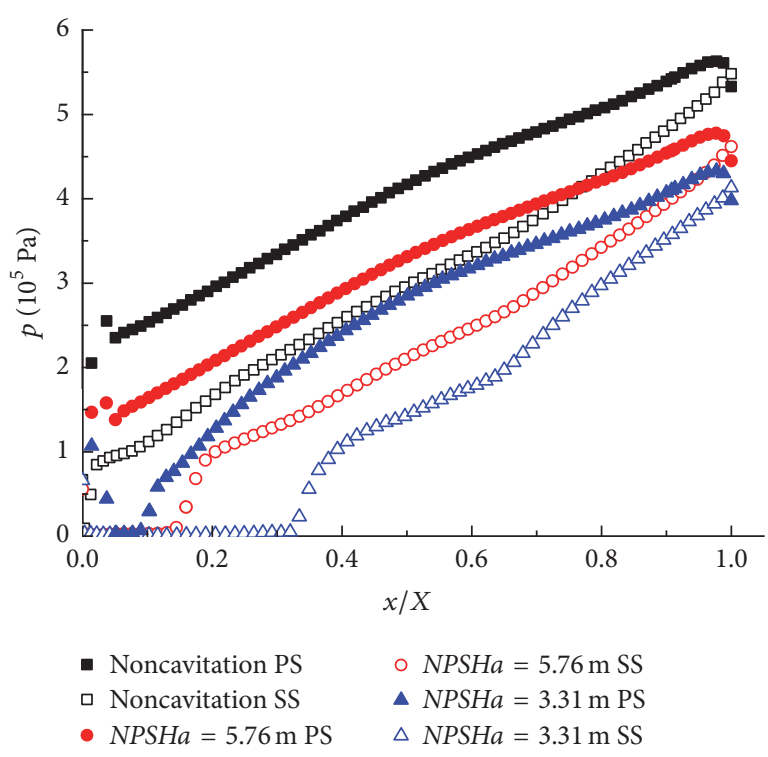

(a) Original blade

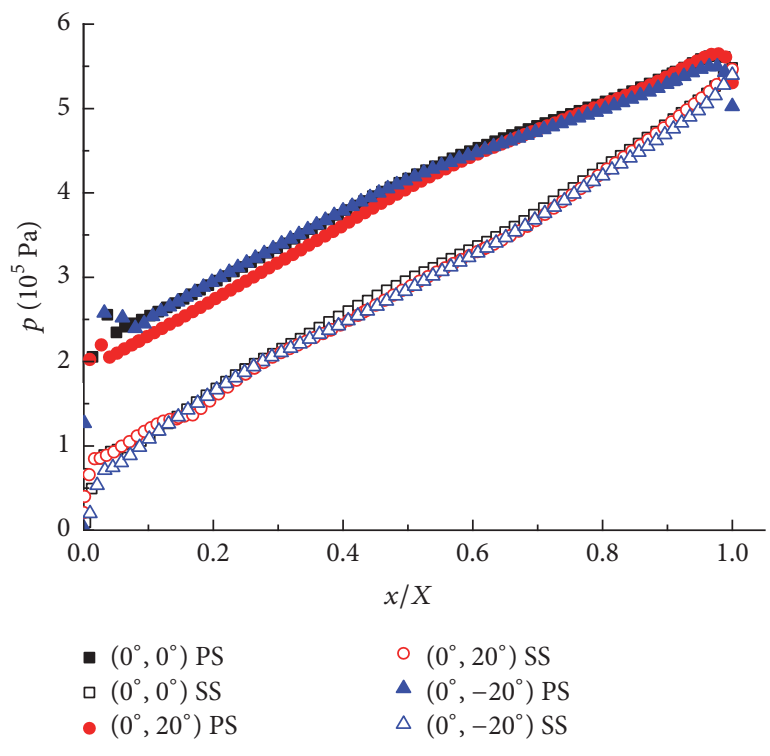

(c) Blades FS and BS $20^{\circ}$ along the hub at noncavitation state

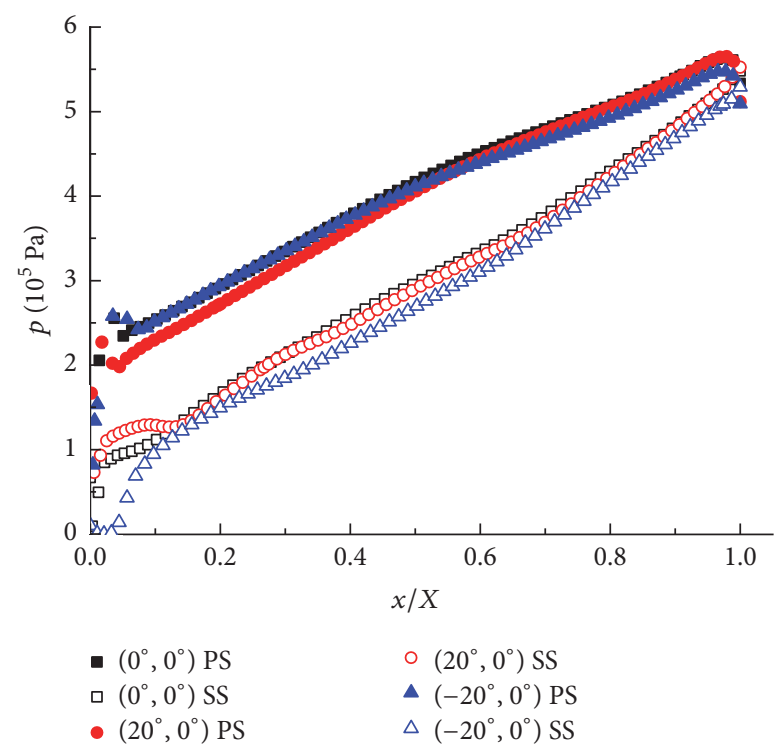

(b) Blades FS and BS $20^{\circ}$ along the shroud at noncavitation state

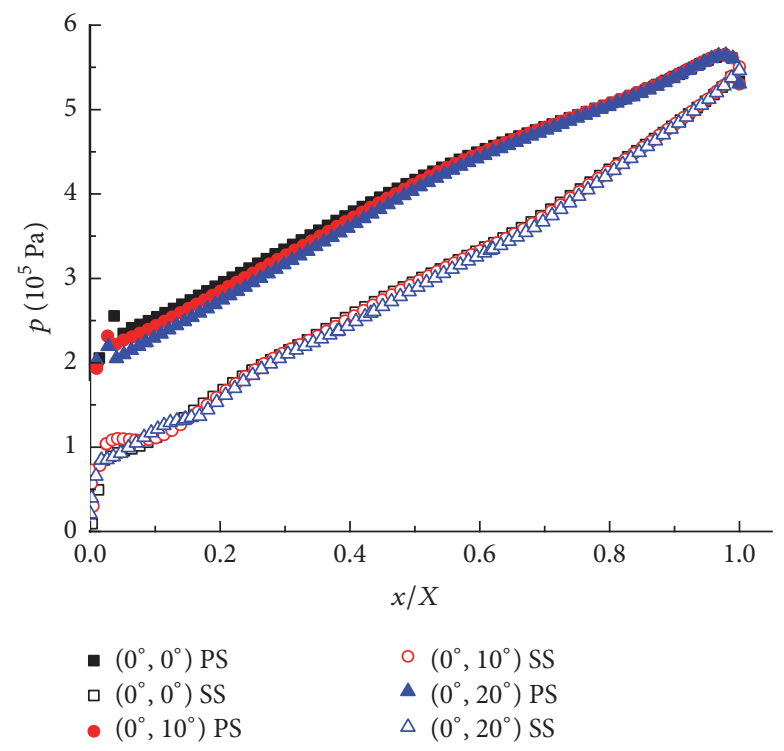

(d) Blade FS along the hub at noncavitation state

FIGURE 5: Blade load distribution of different blade leading edge at midspan.

declines. The pressure at the area which is covered by cavitation bubbles is almost zero. So the degree of cavitation on the blade can be judged by the distribution of blade load.

As shown in Figure 5(b), the blade FS along the shroud leads to the decline of pressure on pressure side, and the decline degree is larger at front and central part of blade. Comparing with the original blade, the pressure on suction side is lower partially at central and rear part of blade but is higher at the entrance. When the pressure at centrifugal pump entrance declines, the probability of bubbles generating on the original blade is higher than the FS blade along the shroud. So the cavitation performance of centrifugal is improved greatly. The pressure on pressure side is almost the same at the front of blade and low at the central and rear of blade, when the blade is $\mathrm{BF}$ along the shroud. The pressure on the suction side declines apparently especially at the entrance that leads to a bad cavitation performance.

In Figure 5(c), the pressure on the pressure side at the front and central part of blade declines apparently, but it is almost the same at the rear of blade, when the blade is FS along the hub. So the change of cavitation performance is not obvious. When the blade is BS along the hub, the pressure on the suction side at the entrance is lower than the original blade. So the cavitation performance of it is bad. As shown in Figure 5(d), appropriate FS angle along the hub can improve the cavitation performance slightly.

Therefore, the cavitation performance can be judged by the blade load distribution at midspan in the state of noncavitation. 


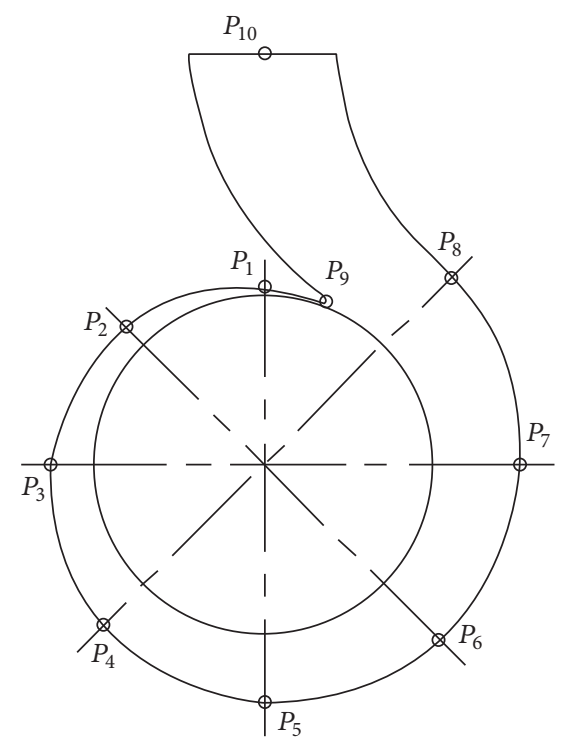

FIGURE 6: Distribution of monitoring points in the volute.

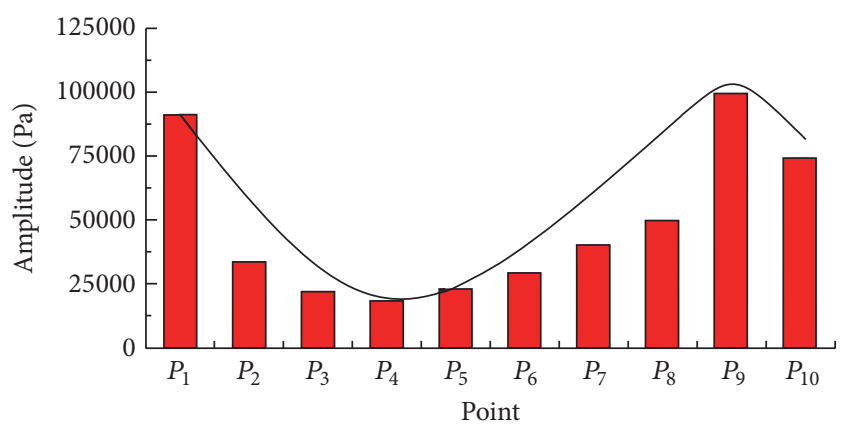

FIGURE 7: Pressure pulsation amplitude of points in volute.

4.3. Analysis of Pressure Pulsation in Volute. The pressure pulsation generates in centrifugal pump because of the asymmetry of volute passageway and the rotor-stator interactions between impeller and volute. In the state of cavitation, the development and collapse of cavitation bubbles have effect on the pressure pulsation in the centrifugal pump.

10 monitoring points are set up to monitor the pressure pulsation in the flow field of volute, as shown in Figure 6. The pressure pulsation amplitude of points in volute is shown in Figure 7, which presents that the tongue (Point $P_{9}$ ) has great effect on the pressure pulsation of the volute.

The maximum pressure pulsation amplitude is $100726 \mathrm{~Pa}$, which occurred at the tongue. The strength of pressure pulsation is related to the relative distance of tongue. The pressure pulsation near the tongue is stronger than other areas because of the asymmetry of volute passageway. So the rotor-stator interaction is most intensive and the fluid is most restricted at the tongue. Excitation produced by pressure pulsation at the tongue has great effect on the vibration and noise of centrifugal pump, and along with the development of cavitation degree the effect is conspicuous [31]. Therefore, in this paper the pressure pulsation at the tongue (Point $P_{9}$ ) is considered when NPSHa is $3.31 \mathrm{~m}$.
TABLE 2: Maximum pressure pulsation amplitude of different blade samples at $P_{9}$.

\begin{tabular}{lcc}
\hline Blade samples & $\begin{array}{c}\text { Maximum pressure } \\
\text { pulsation }(\mathrm{Pa})\end{array}$ & $\begin{array}{c}\text { Reduction } \\
(\%)\end{array}$ \\
\hline$\left(0^{\circ}, 0^{\circ}\right)$ & 100726 & \\
$\left(-10^{\circ}, 0^{\circ}\right)$ & 104695 & -3.94 \\
$\left(-20^{\circ}, 0^{\circ}\right)$ & 327479 & -225.12 \\
$\left(+10^{\circ}, 0^{\circ}\right)$ & 81347 & 19.24 \\
$\left(+20^{\circ}, 0^{\circ}\right)$ & 74595 & 25.94 \\
\hline
\end{tabular}

The FS and BS blades along the shroud have greater influence on the pressure pulsation than the FS and BS blades along the hub. The influence is shown in Table 2. That presents that the FS blade along the shroud can obviously reduce the maximum pressure pulsation amplitude at the tongue.

The pressure pulsation at $P_{9}$ of different samples is converted to the pressure signal in the frequency domain by the Fast Fourier Transform, as is shown in Figure 8. There are spikes of the pressure pulsation amplitude which are affected by the times of rotation frequency, blade passing frequency, and their harmonic frequencies. The blade passing frequency is $290 \mathrm{~Hz}$ as the rotate speed of impeller is $2900 \mathrm{r} / \mathrm{min}$ and the blade number is 6 . As shown in Figure 8, the blade passing frequency is the main factor to affect the pressure pulsation. And along with the aggravating of the cavitation degree, the pressure pulsation amplitude of blade passing frequency and second harmonics of the blade frequency also increases.

As shown in Figure 8(a), comparing to the original blade, the pressure pulsation amplitude of the FS blade along the shroud is lower that gets a stable cavitation performance. On the contrary, along with the increase of BS angle along the shroud, the pressure pulsation is more aggravated. When $\mathrm{NPSHa}$ is $3.31 \mathrm{~m}$, internal centrifugal pump is on the fullcavitation condition. The bubbles range is wide; therefore the passageway is blocked and the fluid is disturbed in impeller. So the flow state is chaos from blade leading edge to the trailing edge. That can obviously affect the fluid entering the volute and lead to the generation of vortex. So that has effect on the pressure pulsation in volute. And the normal pressure pulsation in centrifugal pump is also disturbed by the falling-off and collapsing of bubbles. So these two reasons make the difference between the pressure pulsations of these samples. The FS and BS blades along the shroud have obvious effect on the pulsation pressure in volute. So the $\left(0^{\circ}, 0^{\circ}\right)$ and $\left( \pm 20^{\circ}, 0^{\circ}\right)$ samples are compared emphatically. The vorticity distributions of the 3 samples are presented in Figure 9. The vortex can be reflected by the strength of vorticity which presents the rotation of fluid velocity vector. The $\left(+20^{\circ}, 0^{\circ}\right)$ sample can obviously reduce the strength of vorticity near the tongue, as shown in Figure 9. So the FS blade along the shroud can make a lower pressure pulsation and get a better cavitation performance than other samples.

Similar to Figure 8(a), Figure 8(b) also shows that the amplitude of the pressure pulsation can reflect the cavitation performance. Along with the increasing of FS angle along the hub, the pressure pulsation amplitude firstly reduces and 


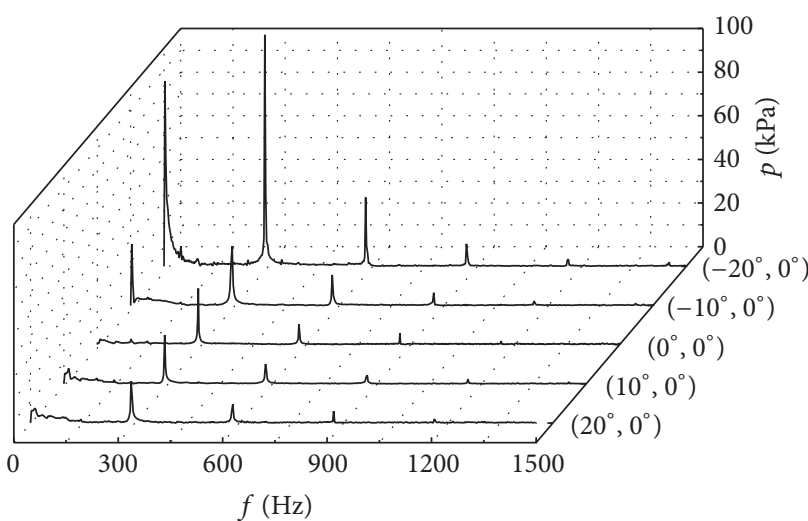

(a) The blades FS and BS along the shroud

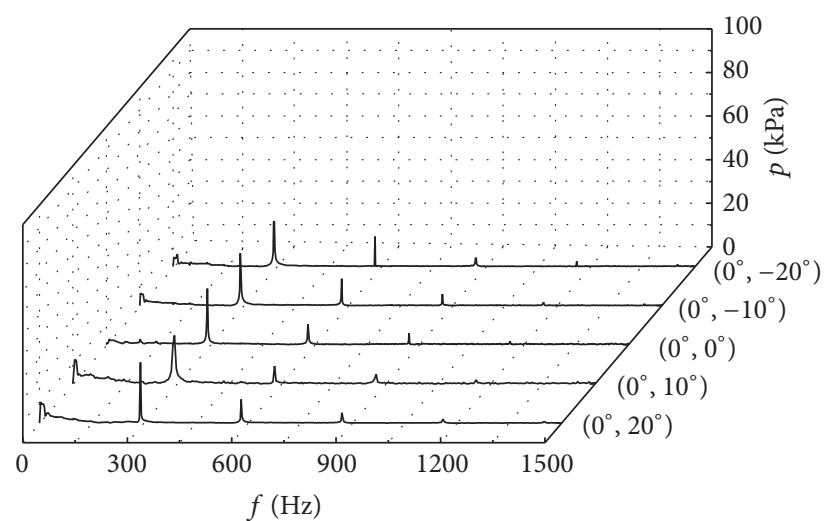

(b) The blades FS and BS along the hub

Figure 8: Frequency domain of pressure pulsation at $P_{9}$ when NPSHa is $3.31 \mathrm{~m}$.

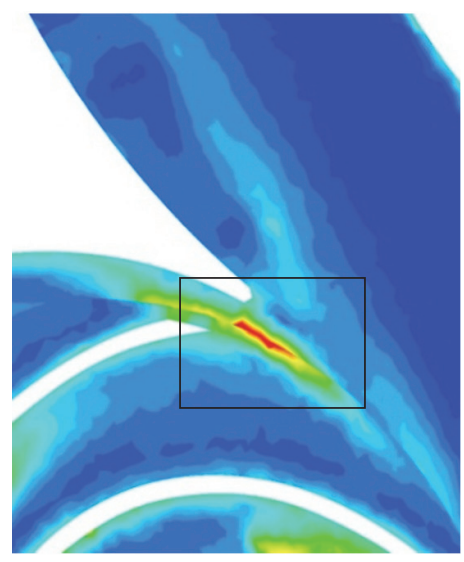

$\left(-20^{\circ}, 0^{\circ}\right)$

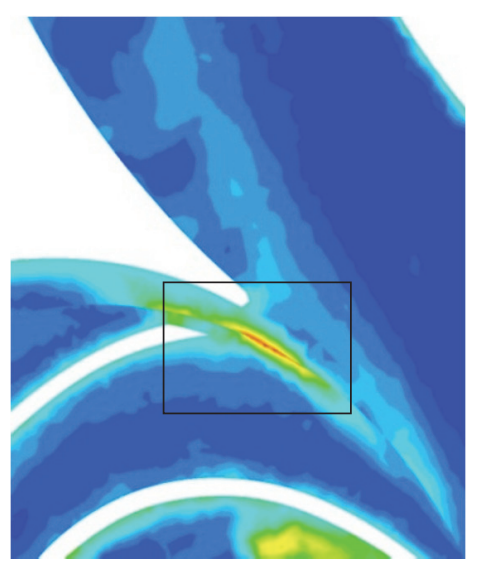

$\left(0^{\circ}, 0^{\circ}\right)$

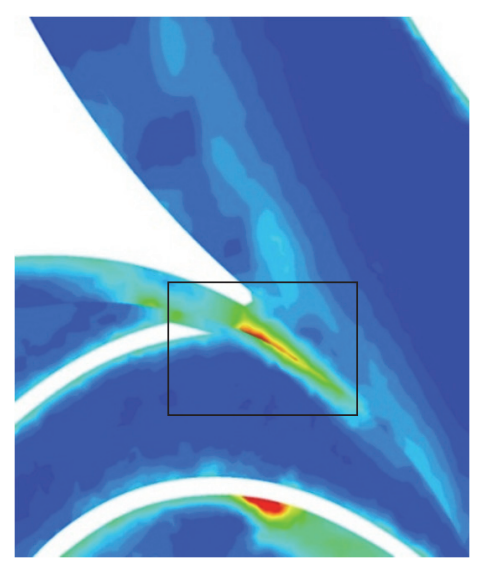

$\left(+20^{\circ}, 0^{\circ}\right)$
$4.828 e+003$

$4.483 e+003$

$4.138 e+003$

$3.793 e+003$

$3.448 e+003$

$3.103 e+003 \frown$

$2.759 e+003$ is

$2.414 e+003$

$2.069 e+003$

$1.724 e+003 \stackrel{2}{>}$

$1.379 e+003$

$1.034 e+003$

$6.897 e+002$

$3.448 e+002$

$0.000 e+000$

FIgURE 9: Vorticity distributions of the pump at midspan when NPSHa is $3.31 \mathrm{~m}$.

then rises. Because the FS and BS along the hub have slight effect on the flow state at impeller entrance, the distribution of vortex is almost the same with the $\left(0^{\circ}, 0^{\circ}\right)$ sample. So the cavitation performance is slightly affected by the position along the hub.

\section{The Radial Basis Function Response Model for Cavitation Performance}

In this research, the effect of blade leading edge shape on cavitation performance is predicted by the Radial Basis Function. Within a certain range, the more the samples are, the more accurate the response model is. The sweep angle along the shroud and the hub is taken as the design variable, and the required cavitation margin NPSHr of centrifugal pump is taken as the response value. The RBF method and the DOE are introduced in detail in Sections 2 and 3. The Radial Basis Function response model is constructed using MATLAB code. The results of response model are shown in Figure 10.

To verify the accuracy of the approximate model, the comparison of the Radial Basis Function response results with the CFD results is shown in Table 3.

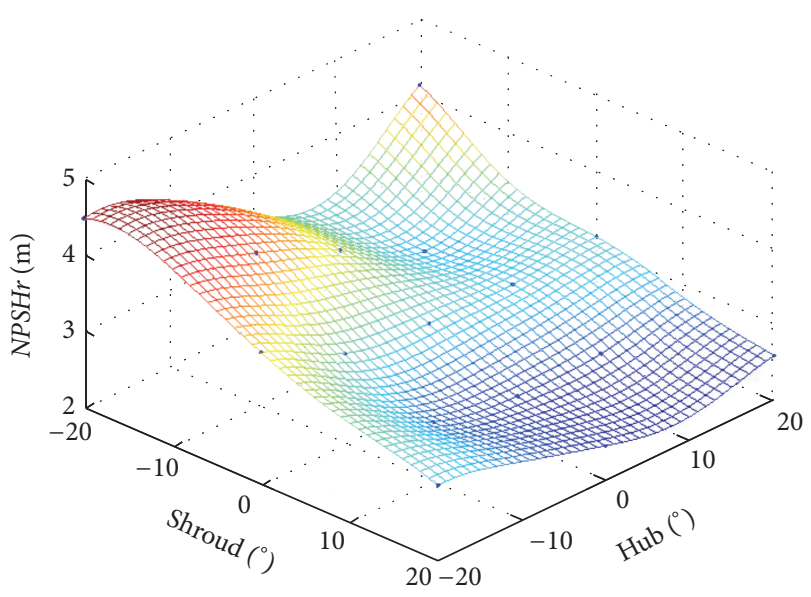

FIGURE 10: Cavitation performance response model by Radial Basis Function.

As shown in Table 3, the maximal relative predicted error is $6.888 \%$. The adjusted coefficient of multiple determination $R_{\text {adj }}^{2}=0.8269$ and the root mean square error RMSE = 
TABLE 3: Comparisons of RBF response model results and CFD results.

\begin{tabular}{lccc}
\hline $\begin{array}{l}\text { Predicted } \\
\text { point }\end{array}$ & $\begin{array}{c}\text { CFD result } \\
\mathrm{m}\end{array}$ & $\begin{array}{c}\text { RBF response } \\
\text { model result } \\
\mathrm{m}\end{array}$ & $\begin{array}{c}\text { Error } \\
\%\end{array}$ \\
\hline$\left(5^{\circ},-5^{\circ}\right)$ & 2.9498 & 2.7741 & 5.896 \\
$\left(-5^{\circ}, 5^{\circ}\right)$ & 3.2061 & 3.1243 & 2.551 \\
$\left(15^{\circ}, 5^{\circ}\right)$ & 2.6011 & 2.4223 & 6.874 \\
$\left(5^{\circ}, 15^{\circ}\right)$ & 2.8893 & 2.9698 & 2.786 \\
$\left(-15^{\circ},-5^{\circ}\right)$ & 3.8245 & 3.9569 & 3.462 \\
$\left(-10^{\circ},-20^{\circ}\right)$ & 4.0259 & 4.3032 & 6.888 \\
\hline
\end{tabular}

0.1306. The proposed $\mathrm{RBF}$ response model is relatively accurate, and the effect of blade leading edge position on the cavitation performance for centrifugal pump can be reflected accurately.

\section{Conclusions}

(i) In this research, the effect of the different blade leading edge shape on pump cavitation performance is investigated. The flow entering impeller has received the energy in advance due to the FS blade along the shroud. The flow state at the impeller entrance is improved, so the cavitation performance is improved. The position of blade leading edge along the hub has slight effect on cavitation performance of centrifugal pump. The appropriate FS angle along the hub can improve the cavitation performance slightly, but when the FS angle along the hub is oversize, the entrance is blocked seriously and the cavitation performance is reduced.

(ii) The cavitation performance can be judged by the blade load distribution. The lower the blade load near the inlet is and the higher the pressure at the suction side is, the better the cavitation performance is.

(iii) Along with the decrease of the cavitation performance, the blade passing frequency and the second harmonics of blade passing frequency in volute are more drastic due to the vortex out of the impeller and the falling-off and collapsing of the bubbles. The state of the cavitation can be reflected by the strength of the pressure pulsation. The FS blade along the shroud has low strength of vorticity and low amplitude of the pressure pulsation in volute which has better cavitation performance than other blade samples.

(iv) The cavitation performance response model based on the Radial Basis Function is established. The sweep angle along the shroud and the hub is taken as the design variable, and the required cavitation margin $\mathrm{NPSHr}$ of centrifugal pump is taken as the response value. The response model is relative accurate. The effect of the shape of blade leading edge on the cavitation performance of centrifugal pump can be accurately predicted.

\section{Competing Interests}

The authors declare that they have no competing interests.

\section{Acknowledgments}

The research is supported by National Natural Science Fund of China (Grant no. 51469014) and National Key Research and Development Program of China (Grant no. 20016YFB0200901). The supports are gratefully acknowledged.

\section{References}

[1] C. E. Brennen, Hydrodynamics of Pumps, Cambridge University Press, New York, NY, USA, 2011.

[2] T. Rus, M. Dular, B. Širok, M. Hočevar, and I. Kern, "An investigation of the relationship between acoustic emission, vibration, noise, and cavitation structures on a Kaplan turbine," Journal of Fluids Engineering, vol. 129, no. 9, pp. 1112-1122, 2007.

[3] S. F. Chini, H. Rahimzadeh, and M. Bahrami, "Cavitation detection of a centrifugal pump using noise spectrum," in Proceedings of the ASME International Design Engineering Technical Conferences and Computers and Information in Engineering Conference (DETC'05), pp. 13-19, American Society of Mechanical Engineers, Long Beach, Calif, USA, September 2005.

[4] S. Christopher and S. Kumaraswamy, "Identification of critical net positive suction head from noise and vibration in a radial flow pump for different leading edge profiles of the vane," Journal of Fluids Engineering, vol. 135, no. 12, Article ID 121301, 2013.

[5] C. E. Brennen, "A review of the dynamics of cavitating pumps," Journal of Fluids Engineering, Transactions of the ASME, vol. 135, no. 6, Article ID 061301, 2013.

[6] Y. A. Bouziad, Physical Modelling of Leading Edge Cavitation: Computational Methodologies and Application to Hydraulic Machinery, Université Paris VI, Paris, France, 2006.

[7] B. Schiavello and F. C. Visser, "Pump cavitation-various NPSHr criteria, NPSHa margins, and impeller life expectancy," in Proceedings of the 25th International Pump Users Symposium, Turbomachinery Laboratory, Texas A\&M University, College Station, pp. 113-144, Houston, Tex, USA, February 2009.

[8] Z. P. Wei, H. P. Wan, S. J. Xu et al., "The analysis of effect factors on cavitation performance for centrifugal pump," General Machinery, no. 4, pp. 86-88, 2011.

[9] A. J. Acosta, Y. Tsujimoto, Y. Yoshida, S. Azuma, and P. Cooper, "Effects of leading edge sweep on the cavitating characteristics of inducer pumps," International Journal of Rotating Machinery, vol. 7, no. 6, pp. 397-404, 2001.

[10] F. Bakir, S. Kouidri, R. Noguera, and R. Rey, "Experimental analysis of an axial inducer influence of the shape of the blade leading edge on the performances in cavitating regime," Journal of Fluids Engineering, vol. 125, no. 2, pp. 293-301, 2003.

[11] R. Balasubramanian, S. Bradshaw, and E. Sabini, "Influence of impeller leading edge profiles on cavitation and suction performance," in Proceedings of the 27th International Pump Users Symposium, pp. 12-15, Houston, Tex, USA, September 2011.

[12] Z. L. Fan, W. G. Li, and J. X. Xue, "The influence of the shape of blade inlet edge on NPSH of centrifugal pump," Journal of Gansu University of Technology, vol. 20, no. 1, pp. 44-47, 1994. 
[13] J. H. Yang, Y. Wang, B. Guo et al., "Research on influence of blade inlet position of double-suction pump performance," Fluid Machinery, vol. 41, no. 1, pp. 49-52, 2013.

[14] X. W. Luo, Y. Zhang, J. Peng, H. Xu, and W. Yu, "Impeller inlet geometry effect on performance improvement for centrifugal pumps," Journal of Mechanical Science and Technology, vol. 22, no. 10, pp. 1971-1976, 2008.

[15] R. Franke, "Scattered data interpolation: tests of some methods," Mathematics of Computation, vol. 38, no. 157, pp. 181-200, 1982.

[16] G. Turk and J. F. O’brien, Variational Implicit Surface, Georgia Institute of Technology, 1999.

[17] M. D. Buhmann, "Radial basis functions," Acta Numerica, vol. 9, pp. 1-38, 2000.

[18] B. S. Morse, T. S. Yoo, P. Rheingans et al., "Interpolating implicit surfaces from scattered surface data using compactly supported radial basis functions," in Proceedings of the International Conference on Shape Modeling and Applications, pp. 89-98, Cambridge, Mass, USA, June 2005.

[19] R. J. Pan, X. X. Meng, and T. K. Whangbo, "Hermite variational implicit surface reconstruction," Science in China, Series F: Information Sciences, vol. 52, no. 2, pp. 308-315, 2009.

[20] N. Kojekine, V. Savchenko, and I. Hagiwara, "Surface reconstruction based on compactly supported radial basis functions," in Geometric Modeling: Techniques, Applications, Systems and Tools, pp. 217-231, Springer, Amsterdam, The Netherlands, 2004.

[21] S. J. Liu and X. R. Liu, "Fast Hermite radial basis function surface reconstruction," Science China, vol. 44, no. 11, pp. 14091421, 2014.

[22] Y. Sun, X. G. Deng, G. X. Wang, Y. Wang, and M. Mao, "Improvement on Delaunay graph mapping dynamic grid method based on radial basis functions," Acta Aeronautica et Astronautica Sinica, vol. 35, no. 3, pp. 727-735, 2014.

[23] L. Xie, M. Xu, B. Zhang, and X.-M. An, "Space points reduction in grid deforming method based on radial basis functions," Journal of Vibration and Shock, vol. 32, no. 10, pp. 141-145, 2013.

[24] G. Wang, B. Q. Lei, and Z. Y. Ye, "An efficient deformation technique for hybrid unstructured grid using radial basis functions," Journal of Northwestern Polytechnical University, vol. 29, no. 5, pp. 783-788, 2011.

[25] E. Acar, "Optimizing the shape parameters of radial basis functions: an application to automobile crashworthiness," Proceedings of the Institution of Mechanical Engineers, Part D: Journal of Automobile Engineering, vol. 224, no. 12, pp. 15411553, 2010.

[26] S. B. Yao, D. L. Guo, and G. W. Yang, "Aerodynamic optimization of high-speed train based on RBF mesh deformation," Chinese Journal of Theoretical and Applied Mechanics, vol. 45, no. 6, pp. 982-986, 2013.

[27] B. Su, Q.-Y. Shi, and R.-J. Qian, "Preliminary study on the use of radial basis function in fluid-structure interaction analysis," Engineering Mechanics, vol. 30, no. 1, pp. 59-63, 2013.

[28] Y. Z. Lin, B. Chen, and X. Xu, "Numerical method of aeroelasticity based on radial basis function interpolation," Journal of Beijing University of Aeronautics and Astronautics, vol. 40, no. 7, pp. 953-958, 2014.

[29] H. B. Fang and M. F. Horstemeyer, "Global response approximation with radial basis functions," Engineering Optimization, vol. 38, no. 4, pp. 407-424, 2006.

[30] Y. Wang, H. L. Liu, S. Q. Yuan, M. Tan, and K. Wang, "CFD simulation on cavitation characteristics in centrifugal pump,"
Journal of Drainage and Irrigation Machinery Engineering, vol. 29, no. 2, pp. 99-103, 2011.

[31] B. Gao, X. Sun, M. Yang, and N. Zhang, "Characteristics of unsteady excitation induced by cavitating flow in centrifugal pumps," Journal of Mechanical Engineering, vol. 50, no. 16, pp. 199-205, 2014. 


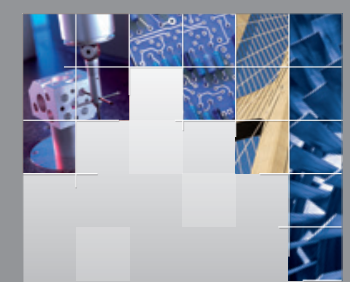

\section{Enfincering}
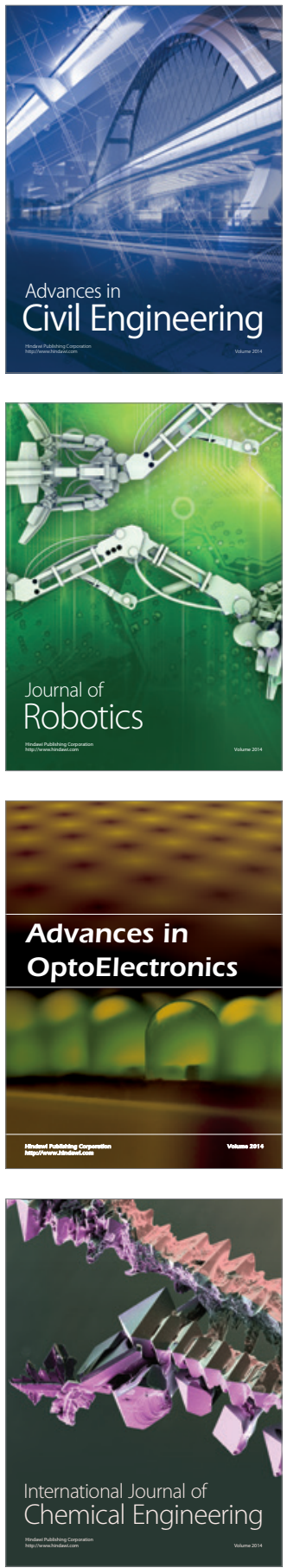

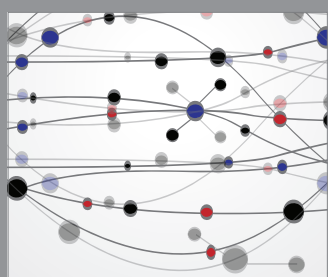

The Scientific World Journal

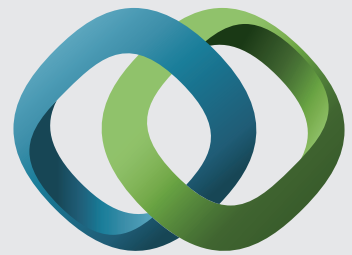

\section{Hindawi}

Submit your manuscripts at

http://www.hindawi.com
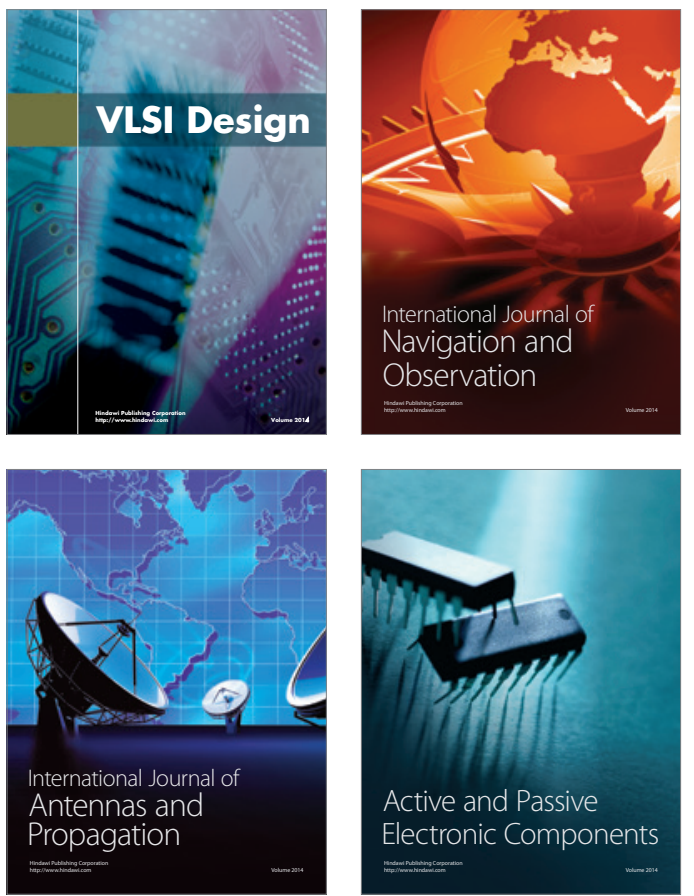
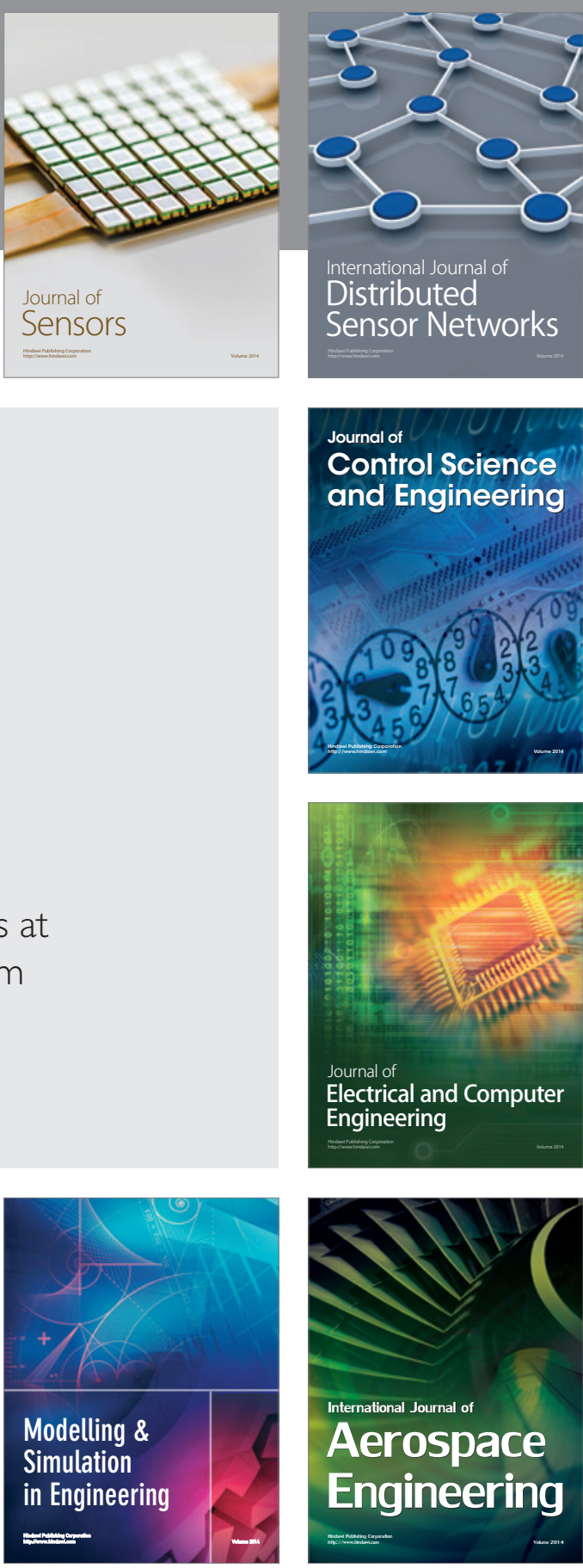

International Journal of

Distributed

Sensor Networks

Journal of

Control Science

and Engineering
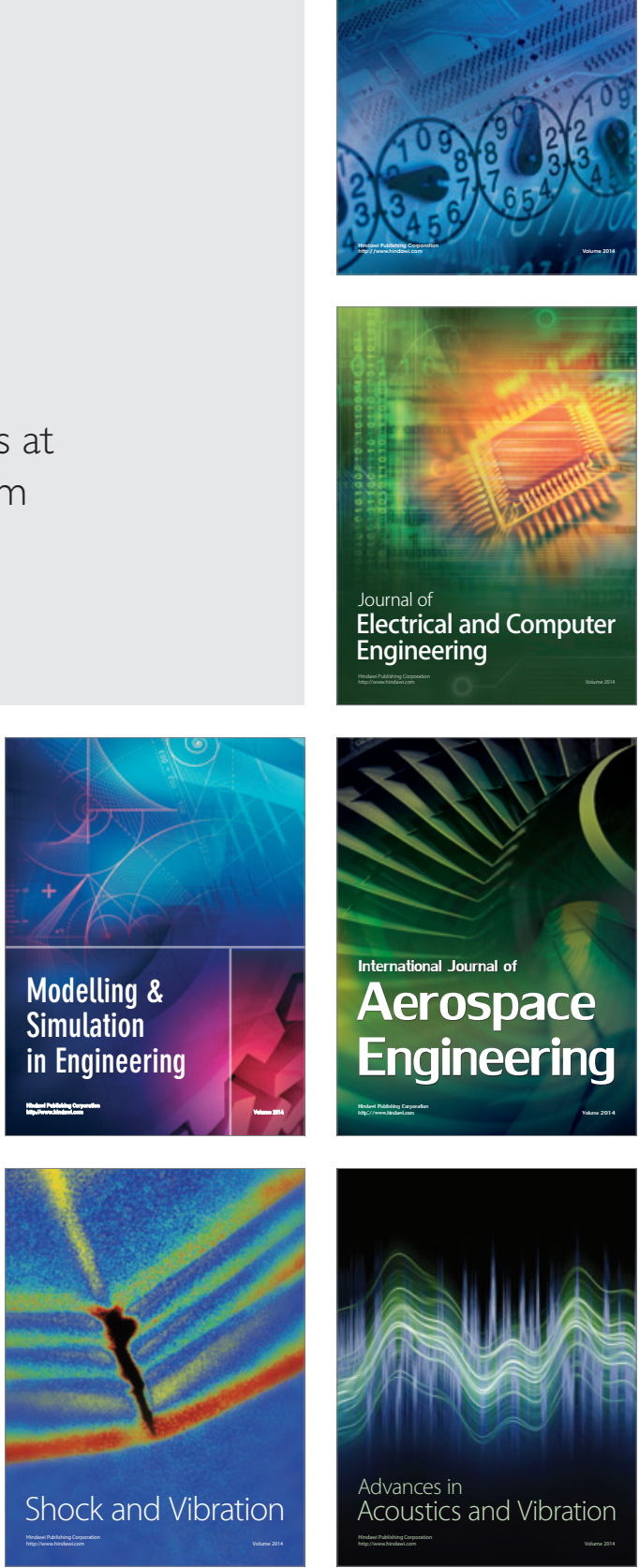